\title{
PROBLEM-BASED LEARNING (PBL) LANGUAGE CASE-CRAFTING MODEL (PBL-LCCRAFT): LANGUAGE-IN-USE AND THE 3R
}

\author{
Suraini Mohd-Ali ${ }^{1 *}$, Hazleena Baharun ${ }^{2}$, Haliza Harun ${ }^{3,}$ Ramiaida Darmi ${ }^{4,}$ Noor Saazai \\ Mat Saad ${ }^{5}$, Fariza Puteh-Behak ${ }^{6}$,Norhaili Massari ${ }^{7}$ and Normazla Ahmad Mahir ${ }^{8}$ \\ 1Dr., Universiti Sains Islam Malaysia (USIM), MALAYSIA, suraini@usim.edu.my \\ ${ }^{2}$ Dr., Universiti Sains Islam Malaysia (USIM), MALAYSIA, hazleena@usim.edu.my \\ ${ }^{3}$ Dr., Universiti Sains Islam Malaysia (USIM), MALAYSIA, haliza@usim.edu.my \\ ${ }^{4}$ Dr., Universiti Sains Islam Malaysia (USIM), MALAYSIA, ramiaida@usim.edu.my \\ ${ }^{5}$ Dr., Universiti Sains Islam Malaysia (USIM), MALAYSIA, noorsaazai@usim.edu.my \\ ${ }^{6}$ Dr., Universiti Sains Islam Malaysia (USIM), MALAYSIA, fariza@usim.edu.my \\ ${ }^{7}$ Ms., Universiti Sains Islam Malaysia (USIM), MALAYSIA, norhaili@usim.edu.my \\ ${ }^{8}$ Ms., Universiti Sains Islam Malaysia (USIM), MALAYSIA, normazla@usim.edu.my \\ ${ }^{*}$ Corresponding author
}

\begin{abstract}
This article describes a new PBL case design model for language practitioners that emerged from an action research project on PBL case-design training for language practitioners. Participants of the action research project underwent two cycles of PBL case-design training. Data collection tools consisting of an observation checklist and a series of focus group interview were used to collect data from the participants. Data gathered were then analyzed using content analysis for emerging themes. Findings revealed that modification to the model used is needed to suit the needs of language practitioners in crafting cases for language classroom use. Known as the Problem-Based Learning (PBL) Language Case Crafting Model (PBL-LCCRAFT), this new model is an extension from the original model used to train the participants, the 3C3R case-design model (Hung, 2006). While maintaining some components from the original 3C3R case-design model, the PBL-LCCRAFT model further extends the original model by including components which are found to be very much relevant to language practitioners to craft PBL cases to be used in language classrooms. This paper aims to discuss one major component incorporated into the new model (i.e. Language-in-Use) to demonstrate language practice in meaningful contexts. It illustrates the significant and strong link between the existing components from the 3C3R case-design model (i.e. 3R-Researching, Reasoning and Reflecting) with the newly incorporated one (i.e. Language-in-Use) in the realm of language teaching and learning. It is hoped that all the components in the PBL-LCCRAFT model, will be able to serve as a guide for language practitioners in crafting PBL cases to meet their learners' language learning aims.
\end{abstract}

Keywords: Problem-Based Learning (PBL), PBL-LcCRAFT model, Language in-use, 3R component. 


\section{INTRODUCTION}

Problem based learning (PBL) is a pedagogical approach used by many educators particularly to teach content area subjects. It was first developed by Barrows (1986) to find a more practical, hands-on approach to teach student doctors as opposed to listening to traditional lectures. Following its success in the medical field, this pedagogical approach has been used extensively in many other content areas such as nursing, engineering, science, mathematics, and history among others. In PBL, students work together to find possible and potential solutions to a complex problem. The given "problem" is used as the starting point to teach a set of learning objectives (Ferreira \& Trudel, 2012). Studies have shown that PBL can positively impact problem-solving and collaboration skills (Achilles \& Hoover, 1996; Ben-Chaim, Fey, Fitzgerald, Benedetto \& Miller, 1998; Mohd lqbal Mohd Caesar et. al, 2016), content retention (Saye \& Brush, 1999; Schneider, Krajcik, Marxk \& Soloway, 2002), self-efficacy (Cerezo, 2004), and transfer of learning (Pedersen \& Liu, 2003).

Despite the many benefits of using PBL, crafting PBL cases is challenging as cases need to be carefully designed and crafted to achieve the learning objectives. One main problem faced by PBL practitioners particularly novice practitioners, is in crafting challenging yet appropriate problems to be used in the classrooms. There are many conceptual frameworks proposed by researchers and practitioners as guides to design effective PBL problems. Some are domain-specific in which they are suitable to be used for specific areas only. For example, specifically designed for nursing education, Drummond-Young and Mohide (2001) proposed an eight-step PBL problem development process. Similarly, a conceptual framework developed by the Graduate School of Medicine, The University of Queensland especially for medical lecturers to craft cases for student doctors. There are also conceptual frameworks which are generic or multi-disciplinary in nature which can be used in designing problems in PBL for areas such as management, teacher education and engineering among others.

\section{THE STUDY}

Using suitable framework, PBL practitioners need to be trained or guided to craft PBL cases. The aim of the training is to guide them to design problems to be used in their classrooms. For language practitioners, choosing a suitable framework has always been a problem as the focus for language learning and teaching is different compared to content subject areas. This is because for content subjects, there is 'content' to be the subject matter in the PBL cases whereas, in languages (specifically for general language proficiency courses) there is no specific 'content'. To the best of our knowledge, there is no such framework available for language practitioners to use as a guide in crafting PBL cases. Hence, to train our research participants who are novice PBL language practitioners to craft PBL cases, we decided to use a conceptual framework developed by Hung (2006) known as the 3C3R model. The 3C3R model consists of two main components (Fig. 1); the core components and the processing components. The core components include content, context and connection. They are used to support content/concept learning. Primarily, they are "concerned with the issues of appropriateness and sufficiency of content knowledge, knowledge contextualization, and knowledge integration" (p.57). The processing components on the other hand, include researching, reasoning and reflecting. The focus of the processing components is on learners' cognitive processes of learning and problem-solving skills.

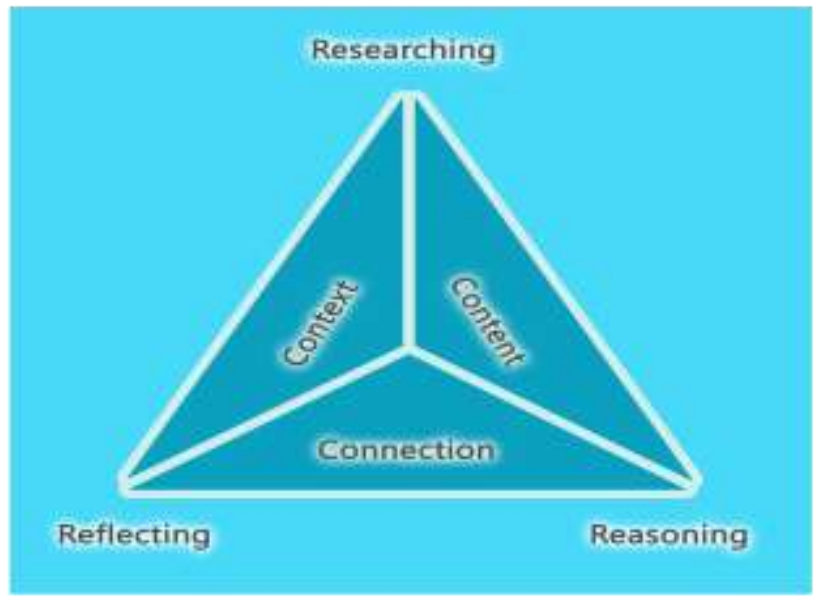

Fig. 1: The 3C3R case design model (Hung, 2006) 
Eight English language practitioners, who have been in the ESL teaching field at tertiary level for at least 10 years, took part in the training sessions. They have little or no PBL knowledge prior to the training. The training was conducted using the Action Research approach (Mohd-Ali et. al, 2017a, 2017b). The four steps (planning, action, observation and reflect) were closely followed within two cycles of the action research procedure.

Training the participants to craft PBL cases using the 3C3R model for language classes was one of the focuses of the study. An equally important aim was to tap into the experiences of the participants to understand the challenges faced by them in crafting PBL cases for language classes. Thus, the instruments used to collect data include observation checklist and focus groups interviews. Open-ended questions were used in the interviews as they provided parameters within which interviewees could formulate answers in their own words (Mohd-Ali et. al, 2016).

The observation checklist consisted of items to be observed: the challenges experienced by the participants to craft the PBL cases and the feasibility of the components in the 3C3R case-design model in assisting them to craft PBL cases. The researchers documented their observations during the training sessions and interviewed the participants using data from the observations as prompts. The participants were interviewed to explore their experiences in the training sessions and the feasibility of the 3C3R case-design model in helping them to craft PBL cases for their language classes. They were asked to reflect on their experiences using the $3 \mathrm{C} 3 \mathrm{R}$ model to craft PBL cases as well as the challenges faced. This was to answer the following research question:

\section{What are the English Language practitioners' experiences in the PBL case-design training?}

In the attempt to explore the participants' experiences when using the 3C3R model in crafting cases for language classes, analysis of the focus group interviews was conducted. Responses of the participants obtained from a series of focus group interviews were transcribed verbatim to produce protocols for the content analysis. The emerging themes gathered from the analysis were documented and analysed.

\section{FINDINGS}

Based on the participants' feedback during the focus group interview gathered during the PBL language cases crafting sessions, we found that crafting cases for language courses was slightly different compared to crafting cases for content subjects (Mohd-Ali et. al, 2017b). Inclusion of new components was needed which led to the emerging of a PBL language case-design model. While maintaining some components from the original 3C3R case-design model, the PBL-LCCRAFT model further extends the original by including components which are found to be very much relevant to language practitioners to craft PBL cases to be used in language classrooms. However, the focus of this section is on Language-In-Use (one of the added components to the new PBL case-crafting model) which has a significant and strong link in the realm of language teaching and learning.

\subsection{Importance of Language-in-Use Component}

In the existing 3C3R Model (Hung, 2006), emphasis was given to the content, context and connection of the crafted cases (3Cs) to encourage learners to engage effectively (i.e. reflect, reason and conduct research $(3 R s))$ in meaningful learning whilst at the same time acquire the target knowledge. However, as language learning requires learners to learn and acquire the target language, there is then a need for considerations to be taken to address the language needs required by learners in learning the target language when crafting $\mathrm{PBL}$ cases as mentioned by the participants during the focus group interview sessions.

As shown in the following excerpt, Teacher $\mathrm{J}$ highlighted the importance of language use in crafting a language learning activity that is based on PBL.

$\mathrm{J}: \ldots$ and I believe that language is the main focus that you have to think about when you design the PBL case. We're thinking, alright, that is the problem, we have to think about the learning outcomes which is language learning. We have to think about what language item that we want them to use in that context or whether that particular problem will stimulate language use. So I think, this is one essential part that I will consider when I am coming out with a model for PBL case design.

Similar view was also voiced by other teachers, regarding the importance of language use in comparison to the content element outlined in the PBL 3C3R model, when crafting cases for language classroom use. This issue was notably expressed by Teachers $B$ and $A$ as shown in the following excerpts.

$B$ : Because in order to solve the problems we need to use language, language use is (chuckle) is every where 
A: True, because don't teach content like other faculties.

(PCDW1-Group A)

In the following excerpt, the teachers pointed out the significance of language use to help solve and complete the task.

B: ...during the problem solving process, the students will use language.

A: Everything that they know.

$B:$ Yes, they will use language to solve and complete the task.

A: ...we can be quite certain that at least some usage of whatever language item of the target language that we want to focus, they will use.

(PCDW1-Group A)

Importantly, majority of the teachers agrees that language use is an essential element to be included in the existing model, as it is the heart of meaningful language learning task within the PBL teaching and learning activities.

\subsection{Language-in-Use and Context}

In ensuring that learners not only become proficient language users and effective problem solvers in specific situational knowledge, the element of 'Context' plays a significant role for learners to practice their language use. The Context needs to be carefully determined to ensure language use is meaningful and authentic when learners attempt solving the problems given to them. This was highlighted by Teacher $\mathrm{J}$ :

$\mathrm{J}$ : ... our main aim is to teach language and we want the students to use the language, not just learn it. So when we want to design our problem, we have to think of the kind of language we expect the students will use and also the language we want them to use. So, context here is important because it will determine the kind of language our students will use. Both actually complement one another.

(PCDW1-Group A)

Thus, it clearly shows the importance of emphasising the 'language-in-use' element when identifying the context to be used by the L2 learners in their PBL language lesson.

\subsection{Language-in-Use and Crafting III-Structured Problems}

More importantly, in setting up a context that allows learners to link the knowledge that they have constructed with the relevant knowledge of the language needed, considerations of language use is at the centre when crafting the ill-structured problems. 'Ill-structured problems' means problems / PBL cases that do not have sufficient information to manage or solve the problems. In other words, the information in the problems / PBL cases are not "well-structured" so that the students will have to search for more information to solve or manage the PBL cases. The participants shared similar view on the need to consider the language use when crafting ill-structured problems. This is exhibited in the following excerpts.

A: ... I think that the kind of question needs to be very well thought of. So, they are aware of the kind of grammar that they have...err... that kind of grammar structure that they have to use.

B: So, they are forced to?

A: Yes, in a way they are forced to. And the problems will sort of provide guidance on the kind of grammar to use. For example, in the problem we have words like "what we can do" or "what will you do", students will know that they need to use the future tense

(PCDW1-Group A)

$\mathrm{J}$ : I think the PBL case itself can be the prompt because I was thinking about one of the PBL cases that we worked on. They need to use present tense and we need to talk about Islamic Phobia and what can academicians do to address this problem so on and so forth. And our prompt was they have to go and do an oral presentation. This will involve forum, and there may be some sort of visual presentation because they need to present orally, and they will discuss what the university needs to do. So, the prompt will in a way tell them the kind of tenses to use when they present.

(PCDW1-Group A) 
In other words, the contextual information found in the problem crafted, will subsequently provide the learners the link of required knowledge of the language use needed with the related situations in real life. Within this view, learners may not only become more aware of the language items needed to address the problem identified, but they will also have the opportunity to observe and use the target language in a reallife context.

\subsection{Definition of Language-in-Use}

Language-in-use within this view, is identified as not only the target language that learners used to access and present the relevant information gained but also that of what they have acquired along the process. As shown in the following excerpt, language-in-use includes the language aim of the lesson as well as other language items the learners might have to use.

$\mathrm{J}$ : You know when we are talking about language-in-use, for an activity like this, students will use English because this is an English language lesson, whatever that they have in the language or whatever they can access. So, to review is maybe to polish up their knowledge and to practise is also to put it into use. So, language-in-use refers to them using the language, not only the one that we are focusing on or targeting on. But also on general English usage.

(PCDW1-Group A)

This also includes the relevant set of vocabulary items needed in effectively solving the problem in question as pointed out in the following excerpt.

$\mathrm{J}$ : ...But let's say they want to say something, they discover they didn't have the vocabulary or the knowledge for that. So, in a way language-in-use refers to also what they need to learn, the words, to get it done.

\section{$\mathrm{K}$ : What they discover along the way?}

J: Yes.

(PCDW1-Group A)

Apart from the relevant vocabulary items needed, language-in-use also encompasses the grammatical knowledge that learners have about the target language, which in turn manifested in learners' production of the language:

$\mathrm{K}$ : Yup, in order for them to solve problems, we already have in mind that students have to use present tense part of speech. Let say they are presenting their ideas, they can use other type of tenses if they have the knowledge.

(PCDW1-Group A)

Findings reveal that there is a crucial need for modification to the existing $3 \mathrm{C} 3 \mathrm{R}$ model to suit language learning needs. The above findings indicate that language-in-use is a crucial element that is needed in crafting the cases in the language learning context. As learning a language requires learners to not only acquire the necessary language input, but also have the opportunity to practise the target language in meaningful context that reflects the authentic context found outside the language classroom, crafting a case that concentrates on the language-in-use is relevant and much needed in PBL language learning context. Accordingly, the emerging model, known as PBL-LcCRAFT model, addresses the gap that exists when crafting meaningful language learning activities within the approach of PBL.

\section{A NEW PBL CASE DESIGN MODEL FOR LANGUAGE PRACTITIONERS}

This section discusses the new PBL case design model for language practitioners that emerged from the PBL case-design training for language practitioners using the action research approach. Known as the Problem-Based Learning (PBL) Language Case Crafting Model (PBL-LcCRAFT) (Fig. 2), the present model is an extension from the 3C3R case-design model (Hung, 2006). New components were added as they were found to be very much relevant to language practitioners to craft PBL cases to be used in language classrooms. 


\subsection{Problem-Based Learning (PBL) Language Case Crafting Model (PBL-LcCRAFT)}

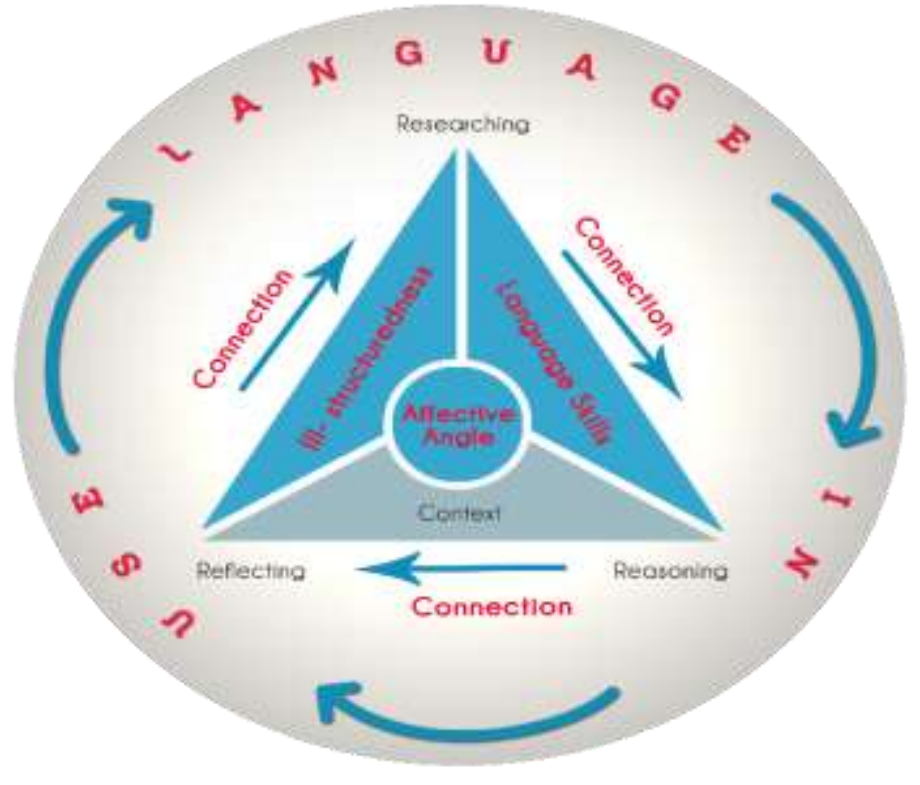

Fig. 2: Problem-Based Learning (PBL) Language Case Crafting Model (PBL-LcCRAFT)

In the PBL-LCCRAFT model, focus is given to the affective angle of designing a language case (Mohd-Ali et. al, 2017a, 2017b). This refers to the psychological needs for competence, relatedness and autonomy to promote motivation. Six elements are identified: subject presence, location proximity, temporal proximity, personal interests, career interests and unsolved problem. Context from the 3C3R case-design model is retained. However, two other 3C3R components - Content and Connection - are replaced with IIIStructuredness and Language Skills (Mohd-Ali et. al, 2017a, 2017b). In the PBL-LcCRAFT model, Context refers to the situational information (based on themes or affective angle chosen); Language Skills refers to the targeted skills or language learning objectives; while III-Structuredness refers to the gaps in the information or lack of details to encourage search for relevant information. The 3Rs in the 3C3R model Researching (finding and locating relevant information), Reasoning (problem solving process) and Reflecting (evaluate information, practices or experiences for future use) - are retained. Throughout the construction of language PBL cases, there is a need to consider the connection among the affective angles of the PBLLcCRAFT model, so that interconnectedness is applied throughout the process of crafting the problems.

The bigger element in crafting a language PBL case is 'Language-in-Use' where the entire focus in designing a PBL case for a language class is on how language is used in the lesson so that language can be practiced in a meaningful context. It is discussed in the following section.

\subsection{The Relationship between 3Rs and Language-in-Use}

Even though the PBL-LcCRAFT model has several new components, the discussion in this section focuses on the relationship between the 3 Rs (i.e. Researching, Reasoning and Reflecting) and Language-in-Use. Language-in-Use that surrounds all the components of the PBL-LcCRAFT model is one major element in the new model. The general purpose of the $3 R$ components is to facilitate meaningful engagement in scientific inquiry and problem-solving processes and to cultivate effective and efficient learners and problem solvers. It is strongly believed that both the Language-in-Use and the 3R components have significant and strong link in the realm of language teaching and learning.

When crafting a PBL language case using the PBL-LcCRAFT model, Language-in-Use is the focus. The main objective is to ensure and enable learners to use language meaningfully when they attempt at the case given to them. Thus, when designing a PBL case for a language classroom, the teacher needs to consider all the 3Rs to ensure language is used by the learners meaningfully. When the case is given to the learners, they are expected to engage in research activities - searching, compiling and reading/synthesizing the information related to the case. These research activities require the learners to use language extensively while engaging in systematic researching processes. This is how Language-in-Use is directly related to one of the 3Rs i.e. Researching. 
The next component is the Reasoning component. At this stage, the learners engage in problem solving processes. They apply the information gathered during the Researching stage to solve the case. The learners analyze information and generate, test and hypothesize solutions. They put their knowledge into practice rather than just memorizing it. Language is put into use when they deliberate and discuss with their group members. Both Researching and Reasoning processes occur simultaneously and reiteratively, and they complement each other in enabling an effective and efficient problem-solving process (Hung, 2006). In doing both the Rs, language is the vehicle and this is how Language-in-Use is directly related to another one of the 3 Rs i.e. Reasoning.

The Reflecting component refers to when the learners evaluate the information, practices or experiences they have gathered for future use. This is the stage where the PBL process is optimized by ensuring the maximum effects of other components in the PBL case. At this point, learners integrate what they have learned and go beyond the intended scope of the PBL case and develop self-directed learning skills. This includes their reflection on their language use. The reflection component also allows learners to be independent and reflect on their knowledge of their language use.

As shown in the PBL-LCCRAFT model, the 3Rs, Researching, Reasoning and Reflecting, do not function exclusively on their own. Instead, when attempting to solve the given case, they are all connected to one another. Researching refers to finding and locating relevant information, reasoning involves processes in problem solving, while reflecting includes evaluating information, practices or experiences for future use. So, when learners embark on research activities, using the information they have gathered, they engage in problem solving process which requires them to provide reasoning, and they reflect on the information they have as well as the actions taken in solving the case. Connection exhibits the interconnectedness of the $3 R$ s. When doing all the $3 R$ activities, learners read the materials they believe related to the problem, engage in discussion sessions and communicate their ideas. All these require language being used meaningfully. Thus, Language-in-Use is one major component that encircles the whole model.

The incorporation of the Language-in-Use component in the PBL-LcCRAFT model serves as a guide for language practitioners in crafting PBL cases to meet their learners' language learning aims. Not only language learning aims are met, language itself is used meaningfully by the learners and this in itself is very important in language learning.

\section{CONCLUSION}

Designing or crafting problems to be used in PBL classrooms is no small feat. Problems need to be challenging, ill-structured and at the same time designed with specific learning objectives in mind. Thus, it is imperative that novice PBL practitioners undergo training sessions on problem crafting. Using a generic conceptual framework as a guide to train the participants who are language teaching experts, training sessions on problem crafting were conducted and it came to the researchers' attention that modifications needed to be made to the framework used. This was due to the focus of the language teachers aim to achieve in their classrooms. For that reason, a new PBL case design model specifically for language practitioners emerged. The PBL-LCCRAFT model consists of a combination of existing and new components to suit the demands of achieving language learning objectives. It is important that language practitioners include all the components found in the new model when crafting problems for PBL language teaching and learning purposes. In other words, all the different components should exist in the problems crafted for PBL language classroom. All the components in the PBL-LCCRAFT model demonstrate significant and strong link between one another which are especially important in realm of language teaching and learning. It is strongly believed that all the components in the PBL-LCCRAFT model will be able to serve as a guide for language practitioners in crafting PBL cases to meet their learners' language learning aims, not only for the teaching of English but also for all other languages.

\section{ACKNOWLEDGEMENT}

This research was financially supported by Universiti Sains Islam Malaysia (USIM) (Action Research Grant Project PPP/ARG/FPBU/30/19715).

\section{REFERENCE LIST}

Achilles, C. M. \& Hoover, S. P. (1996). Exploring Problem-Based Learning (PBL) in Grades 6-12. Paper presented at the Annual Meeting of the Mid-South Educational Research Association (Tuscaloosa, AL, November 1996). 
Barrows, H. S. (1986). A taxonomy of problem-based learning methods. Medical Education, 20, 481-486.

Ben-Chaim, D., Fey, J. T., Fitzgerald, W. M., Benedetto, C. \& Miller, J. (1998). Proportional reasoning among 7th grade students with different curricular experiences. Educational Studies in Mathematics, 36(3), 247-273.

Cerezo, N. (2004). Problem-based learning in the middle school: A research case study of the perceptions of at-risk females. Research in Middle Level Education Online, 27(1). Retrieved April 11, 2017, from http://www.nmsa.org/Publications/RMLEOnline/tabid/101/Default.aspx

Drummond-Young, M., \& Mohide, E. A. (2001). Developing problems for use in problem-based learning. Transforming nursing education through problem-based learning, 165-191.

Ferreira, M. M. \& Trudel, A. R. (2012). The Impact of Problem-Based Learning (PBL) on Student Attitudes toward Science, Problem-Solving Skills, and Sense of Community in the Classroom. The Journal of Classroom Interaction, 47(1), 23-30.

Hung, W. (2006). The 3C3R Model: A Conceptual Framework for Designing Problems in PBL. Interdisciplinary Journal of Problem-Based Learning, 1(1), 55-77.

Mohd-Ali, S., Puteh-Behak, F., Saad, N. S. M., Darmi, R., Harun, H., \& Samah, R. (2016). Tackling the Issue of Credibility in Phenomenographic Interviewing to Capture Problem-Based Learning (PBL) Experience. Mediterranean Journal of Social Sciences, 7(4), 184.

Mohd-Ali, S., Baharun, H., Harun, H., Saad, N. S. M., Puteh-Behak, F., Massari, N., Darmi, R. \& Ahmad Mahir, N. (2017a). Problem-Based Learning (PBL) Case-Design Training and Model for Language Teachers. Proceeding at the International Conference on Research Developments in Humanities, Social Sciences and Interdisciplinary Studies 2017 (RDHSSIS-17, Bali 8-9 Jan.2017).

Mohd-Ali, S., Baharun, H., Harun, H., Saad, N. S. M., Puteh-Behak, F., Massari, N., Darmi, R. \& Ahmad Mahir, N. (2017b). Problem-Based Learning (PBL) Case-Design Training and Model for Language Teachers, IIOAB Journal, Vol.7, Supp.7, 1-7.

Mohd Iqbal Mohd Caesar, Rosmawijah Jawawi, Rohani Matzin, Masitah Shahrill, Jainatul Halida Jaidin, Lawrence Mundia. (2016). The Benefits of Adopting a Problem-Based Learning Approach on Students' Learning Developments in Secondary Geography Lessons. International Education Studies, 9(2), 51-65.

Pedersen, S. \& Liu, M. (2003). Teachers' beliefs about issues in the implementation of a student-centered learning environment. Educational Technology Research and Development. 51(2), 57-76.

Saye, J. W., \& Brush, T. (1999). Student engagement with social issues in a multimedia-supported learning environment. Theory \& Research in Social Education, 27(4), 472-504.

Schneider, R. M., Krajcik, J., Marx, R. W., \& Soloway, E. (2002). Performance of students in project-based science classrooms on a national measure of science achievement. Journal of Research in Science Teaching, 39(5), 410-422. 